\title{
La Educación Física y su Inserción en el Campo de la Salud Colectiva en Brasil: en Búsqueda de un Diálogo Crítico sobre Interfaces, Pertenencias y Sentidos
}

| ' Marcos Bagrichevsky, ${ }^{2}$ Adriana Estevão, ${ }^{3}$ Alexandre Palma |

Resumo: Se pretende suscitar una reflexión crítica sobre las concepciones vigentes sobre salud y cuerpo en la Educación Física (EF) brasileña, analizando también limitaciones y necesidades en las investigaciones relacionadas al tema, con el propósito de sugerir elementos contextuales para la aproximación del área al campo de la Salud Colectiva. En la actualidad, la Educación Física se viene insertando en el ámbito de las políticas de salud pública del país, mayormente, como promotora de prácticas sistemáticas de actividad física (AF). En cierto sentido, EF y AF han sido confundidas como sinónimos. Este texto busca cuestionar la exclusividad de tal comprensión, a pesar de reconocer rasgos históricos disciplinantes de la EF en su génesis militarista, que justifican en parte esta visión simplista. Propone entonces una análisis contemporánea sintetizada del trío cuerpo-salud-mercado y apunta, finalmente, a que las premisas constitutivas de la Salud Colectiva puedan ofrecer perspectivas políticas y epistemológicas valiosas para legitimar los profesionales y los investigadores de la EF como agentes promotores de conocimientos y prácticas corporales éticas en salud, que respetan y consideran la diversidad sócio-económica y cultural en sus intervenciones en la población.

> Palabras clave: concepciones de salud; cultura corporal; educación física; Salud Colectiva.

\author{
1 Doutor em Saúde da Criança e \\ do Adolescente pela Faculdade \\ de Ciências Médicas da \\ UNICAMP. Docente e \\ Pesquisador do Departamento \\ de Ciências da Saúde e do \\ Mestrado em Desenvolvimento \\ Regional e Meio Ambiente da \\ Universidade Estadual de Santa \\ Cruz. Endereço eletrônico: \\ marcos_bagrichevsky@ \\ yahoo.com.br. \\ 2 Doutora em Ciências Sociais \\ pela PUC-SP. Docente e \\ Pesquisadora da Universidade \\ Regional de Blumenau. \\ ${ }^{3}$ Doutor em Saúde Pública pela \\ Escola Nacional de Saúde \\ Pública da FIOCRUZ. Docente e \\ Pesquisador da Universidade \\ Federal do Rio de Janeiro.
}




\section{Abordaje inicial de algunas cuestiones}

Este texto pretende suscitar una reflexión acerca de las concepciones sobre la salud en la Educación Física brasileña, indicando y problematizando sus limitaciones y posibilidades epistemológicas, con el propósito de sugerir elementos para un análisis contextualizada del fenómeno en el área. Para ello, se busca considerar también algunos referenciales derivados de la Salud Colectiva y de las Ciencias Sociales, puesto que esos campos del conocimiento abarcan discusiones de gran densidad, adquiridas en el enfrentamiento de cuestiones históricas referidas al tema.

De ese modo, nos preocupa registrar la necesidad urgente de repensar algunas de las propuestas teórico-metodológicas actuales en la Educación Física brasileña que delimitan intervenciones que se dicen "Promotoras de la Salud", buscando juntarlas a las perspectivas críticas que están fecundamente diseminadas en la Salud Colectiva.

Un argumento inicial, que parece justificar tal preocupación se basa en el hecho de que la Educación Física en lo Brasil y sus intelectuales figuren tímidamente en el ámbito de la formulación de políticas públicas de la salud en el país, en los tres niveles de gobierno, más aún, se tomamos en cuenta las últimas décadas. El mismo viene ocurriendo en relación a la participación del área en los principales foros, instancias científicos tecnológicos deliberativos del sector de la salud (salvo raras excepciones), como los congresos de la ABRASCO ${ }^{1}$ y de la REDE UNIDA ${ }^{2}$ y, los Manifiestos y Movimientos de las Conferencias Nacionales de la Salud ${ }^{3}$ y del CEBES ${ }^{4}$.

Esta afirmación nos remite al actual déficit del conocimiento en el área sobre la salud pública, que raramente es reconocido como un saber sociológico que expresa necesidades de carácter colectivo. Desde luego que esa tendencia tiene relación con la propia génesis de la Educación Física como campo profesional, que tuvo su orientación formadora guiada por una concepción militar de disciplina y control biopolítico de los cuerpos (FOUCAULT, 1999), el cual buscaba extraerles, al máximo, una función servil y desprovista de sentido crítico. Por lo tanto, no es del todo inesperado que la Educación Física venga apoyando ese legado en su contexto histórico brasileño, teniendo como guía principal los ideales del ejercicio corporal (SOARES, 2003; FRAGA, 2003a; GÓIS JÚNIOR; LOVISOLO, 2003).

En nuestros días aún es notorio el predominio de los enfoques en la investigación en este campo que consideran los determinantes biológicos, en prejuicio del abordaje 
de los elementos socio-culturales y políticos que intervienen en el proceso saludenfermedad-cuidado. La dimensión exaltada en esa tendencia es la de la "actividad física (o aptitud física) asociada a la salud”, visión que aparece en la mayor parte de la mayoría de las publicaciones en la Educación Física y que busca promover la existencia de una relación de "causa y efecto", casi exclusiva, entre "ejercicio físico" y "salud". En otras palabras, para tales estudios, la salud podría ser tomada a priori, como consecuencia de efectos fisiológicos (mensurables cuantitativamente) producidos por la práctica regular de las actividades físicas sistemáticas.

Tal hecho trae aparejado implicancias delicadas para el campo del conocimiento y de la intervención, puesto que esa interpretación adopta una interpretación parcial/distorsionada de la realidad, que no toma en cuenta, otros factores contextuales relevantes a los cuales las personas están sometidas y que no pueden ser separados de sus cotidianos: distribución desigual del la renda per cápita nacional, nivel de (des)empleo, condiciones sanitarias básicas, condiciones de vivienda, grado de escolaridad y de saber funcional, (in)disponibilidad de tiempo libre, acceso a los servicios de salud y educación, entre otros. Esos también son aspectos que moldean las condiciones de vida humana e por lo tanto, es necesario que sean considerados en cualquier investigación que pretenda establecer razones más consistentes sobre la salud de la población.

Palma (2000) corrobora esa idea, al enunciar que las posibles articulaciones entre actividad física y salud no están dotadas de una supuesta correlación constante de causalidad. Cambiar el foco de la problemática de investigaciones afines, incorporando en el curso del análisis la distribución de parámetros económicos y culturales, puede influenciar, en gran manera, los resultados obtenidos al final de las investigaciones.

Mira (2000) también plantea cuestiones interesantes y pertinentes acerca de las relaciones dispuestas en el binomio "ejercicio físico-salud”. En su trabajo, argumenta que el anuncio de posibles efectos de prevención y protección adicional del ejercicio sobre la salud de las personas "físicamente activas" no pasa de una hipótesis optimista, puesto que la interacción entre los dos factores no puede ser interpretada de forma lineal y determinista. El investigador nos conduce a pensar que sería más razonable considerar, por otro lado, que son los individuos los poseedores del aporte nutricional y financiero y, del tiempo disponible para las actividades de recreación que buscan la práctica sistemática de la actividad física (y no lo contrario). 
Otros estudios (PALMA et al., 2003; 2006) refuerzan esta concepción al demostrar que la cuestión de la adhesión a los ejercicios físicos tiene una dirección específica. El acceso regular a los espacios formales más especializados para las prácticas de ejercicio corporal, como los gimnasios, por ejemplo, está delimitado por algunas características del público que las frecuenta, cuyo perfil corresponde a las clases sociales más favorecidas (las cuales, al mismo tiempo, representan el porcentaje minoritario de la población, si tomamos en cuenta la totalidad demográfica de la sociedad brasileña).

Por lo tanto, no es equivocado conjeturar que los discursos e iniciativas de los programas de promoción de actividad física, que se dicen "para la población" difundidos en los mass media - poseen en verdad, alcance y efectividad limitados a una brecha bien restricta de la sociedad, si consideramos las pésimas condiciones de vida de la mayor parte de los brasileños y el cuadro desolador de pobreza y desigualdades generalizadas que continúa en nuestros días.

Además, esos programas institucionales, que han sido difundidos también por medio de campañas de algunos órganos públicos, pretenden poner énfasis en el ejercicio corporal como parte esencial de un "estilo de vida", otorgándole un carácter de "estatuto" o "modelo" individualista a ser seguido, delante de la énfasis de "combate al sedentarismo". Al promover un vasto repertorio de comportamiento recomendables para la salud, ignoran los factores socio-políticos y financieros del país, en los cuales está inmersa nuestra colectividad (CASTIEL; VASCONCELLOS-SILVA, 2006).

Si por un lado es aceptable en parte la generalización que existen beneficios orgánicos derivados de algunas modalidades de ejercicio físico (en el caso que sean respetados ciertos preceptos), por otro, estos argumentos se vuelven discutibles, en la medida que se pretende sustentar una política conservadora, una dimensión moral que responsabiliza cada persona por su propia dolencia y no toma en consideración la dinámica sistemática y variada que influencia los estados de la enfermedad humana.

Es prudente, en este estadio, hacer una salvedad. El conjunto de argumentos presentados hasta aquí no tiene como intención demostrar que la práctica sistemática de la actividad física es inocua o desprovista de cualquier interferencia positiva sobre el cuerpo humano. La bibliografia científica también presenta trabajos bien llevados a cabo que ponen en evidencia su acción terapéutica beneficiosa 
sobre varias patologías o potenciales efectos nocivos sobre el organismo y por eso mismo, no es nuestra intención negarla. Igualmente no se quiere ignorar o sublimar la considerable tradición que el tema presenta junto a la Educación Física, sea como objeto de investigación o forma de intervención, aún que creemos que algunas reinterpretaciones son indispensables.

Sin embargo, resulta urgente la tarea de analizar cuidadosamente los intentos de hacer masiva una norma moralizadora que promueve el aspecto físico de la "generación salud" y del "estilo de vida saludable/activo", que están en boga en nuestra sociedad contemporánea (PEDRAZ, 2006). Sobretodo, porque se apoyan en la lógica cuantitativa y positivista de estudios científicos publicados en el área, corroborando los slogans de programas institucionales que promueven una imperiosa y inequívoca necesidad de ejercitarse de cualquier manera, en cualquier lugar y en cualquier momento. Pero, principalmente, es complicado estar de acuerdo con una visión desprovista de sentido crítico como es la afirmación que simplemente el hecho de mantenerse "activo" nos garantiza salud. Costa y Venâncio (2004, p. 70) presentan como argumento:

\begin{abstract}
En este momento es importante resaltar la idea central de Habermas sobre el debilitamiento de la acción comunicadora cuando una parte de los profesionales de la Educación Física está dejando de presentar una postura crítica y ética frente a la acción de los medios de comunicación y de los avances biotecnológicos. Estos profesionales se valen paulatinamente del uso de la razón instrumental al exponer y transformar el cuerpo a través de actividad física, dieta, drogas e del consumo de imágenes del ideal de atletas. Ellos corroboran los discursos de control del cuerpo que los medios de comunicación producen cuando hacen de la actividad física (asociada a la biotecnología) una posibilidad de ajustarse al padrón de belleza en nombre de la salud.
\end{abstract}

\title{
El mercado del corpore sano
}

Las afirmaciones anteriores no están fuera de contexto históricamente; por lo contrario, se encuentran delimitadas por una considerable tradición cultural. Los Movimientos Eugenista e Higienista - desarrollados en Brasil en los inicios del siglo XX (SOARES, 2003) - pueden ser considerados los precursores ideológicos de la apología al "estilo del vida activo", cuyos dictámenes impositivos ya se encuentran de tal modo arraigados en el imaginario popular de la sociedad actual, que son capaces de generar un fuerte sentimiento de culpa en las personas que se 
"resisten" a demostrar el deseo en "descubrir" los supuestas beneficios irrefutables proporcionadas a la salud o, cuyos cuerpos se alejan de la normalidad canónica de una silueta siempre delgada, jovial y esbelta.

Para Goldenberg y Ramos (2002, p. 25) "Debido a la más nueva moral, la de la "buena forma", la exposición del cuerpo en nuestro días no exige solamente el control de sus pulsiones sino también el (auto)control de su aspecto físico".

Un pasaje de la obra "Da Educacão Physica", de Fernando de Azevedo (1920, p. 70) ilustra bien el legado eugenista de la salud, asociado a la práctica de actividades físicas y a los valores morales, dejado ya de lado en las primeras décadas del siglo pasado:

Demeny afirma que por medio de esa gimnasia, así caracterizada, se deben adquirirse, sobre el punto de vista, físico-anatómico: [...] la belleza corporal y, bajo el punto de vista psicológico, el coraje, la iniciativa y la voluntad perseverante, o en un palabras, ciertas aptitudes morales, además del equilibrio funcional de los órganos, que es la expresión y el índice de salud del cuerpo y, por fin "la belleza en la forma y en el movimiento". Ella debe, por lo tanto, tender, no al aumento del músculo, y si al desarrollo racional de todos los órganos y de todas las funciones, para llegar, a través de un entrenamiento, es decir, por una progresión lenta, gradual y metódica, a favorecer al desarrollo del sistema nervioso y a la coordinación de sus manifestaciones, y a facilitar así todos los actos de la vida, poniendo una "alma sana en un cuerpo igualmente sano y vigoroso".

Las perspectivas de ejercitación física cobraron fuerza más al final del mismo siglo. A partir de la década de 1980, se dio énfasis a los discursos sobre la necesidad de involucrar más a la población el la práctica de actividades físicas, la cual era apoyada por el argumento utilitario (económico) de convertir a la salud en algo menos costosa para el Estado. Ese Movimiento - Healthism - cuya fuente precursora fueron los Estados Unidos de América, años más tarde pasa a ser denominado en el Brasil "Movimiento de la Salud" (SOARES, 2003; FRAGA, 2003a).

El Movimiento de la Salud está marcado por un perfil de orientación individualista, en prejuicio de la consideración de cuestiones sociales. Así, las intervenciones físicas que se operan sobre el cuerpo, pierden el sentido más colectivo de otros tiempos (del período Higienista, que promovía la soberanía del "Estado-Nación", por intermedio de la "mejora de la raza") y asumen, deliberadamente privilegios fundamentales con lo privado. El Movimento pone en evidencia un carácter simbiótico con diversos sectores mediáticos, los cuales 
lo consideran como potencial brecha de mercado de consumo (GÓIS JÚNIOR; LOVISOLO, 2003).

El personal training sería uno de sus símbolos puntuales en el protagonismo del individualismo exacerbado y de las preocupaciones con el propio cuerpo y del acceso apenas para quien puede pagar por el ofrecimiento de tal servicio. Lovisolo (1999, p. 17) muestra tal noción al afirmar que

Los campos de intervención tienen en las sociedades dichas occidentales, una fuerte tendencia a generar casi interrumpidamente productos o procesos, visto ya sea como ondas de moda que pueden desaparecen rápidamente, ya sea como innovaciones significativas duraderas [...]. Esa dinámica caracteriza áreas tan dispares como las de la [...] educación física e otras. [...] Los medios de comunicación prestan especial atención a los lanzamientos que realizan promesas relacionadas a los valores de la salud y de la longevidad [subrayado por el autor] aparecen como siendo casi los únicos consensuales aunque se encuentren separados de las discusiones sobre el significado de la buena vida o de la vida plena que tal vez ocupasen un lugar más significativo en el pasado. En el área de la educación física, el último producto lanzado en el mercado tal vez sea el del personal training, suscitando discusiones, cursos, debates y experimentaciones.

Esta perspectiva de hacer de la salud un comercio, es susceptible a la crítica. Derivada de la ampliación del concepto de las ideas totalizadoras, asume un carácter emblemático y busca, en última instancia, materializar la obtención de la salud a través de la venta de productos y servicios. Tal argumentación puede ser comprobada, por ejemplo, en las incontables ofertas de actividades físicas en los gimnasios, suplementos alimentarios, remedios para adelgazar, tratamientos en spas, seguros de salud, etc (ILLICH, 1982; LEFÈVRE, 1991; PAIM; ALMEIDA-FILHO, 2000; RESTREPO, 2001).

Sin embargo, Courtine (1995) advierte que esa cultura de consumo no es reciente y ya aparece en la década de 1960, fuertemente circunstanciada en las cuestiones hedonistas del cuerpo y subscrita en el modelo de la american way of life ("estilo de vida americano"). El autor cuenta que

Las ambigüedades de ese hedonismo se inscriben, todavía, literalmente, en su linguaje, es decir, en el carácter paradójico y en la fuerza transformadora de esos enunciados en particular que nos conducen a la búsqueda de un bienestar en la actividad física. Have fun: la alegría es un deber moral, una forma insistente de obligación. En el mismo contexto, el bienestar psicológico (feeling good) es entendido como una consecuencia de la forma física (being in shape) (COURTINE, 1995, p. 101). 
Como nos recuerda Castiel (2003, p. 93)

una crítica común al concepto 'estilo de vida' está referido a su empleo en contextos de miseria y aplicado a grupos sociales donde los márgenes de elección prácticamente no existen. Muchas personas no eligen 'estilos' para llevar sus vidas. No hay opciones disponibles. En verdad, en estas circunstancias, lo que hay son estrategias de supervivencia. [subrayado del autor].

Lefevre (1991, p. 21) también refuerza que ese fenómeno de "comercializar" la salud no se da en forma repentina, sino que por el contrario, éste es fruto de un largo proceso histórico de expropiación de la misma, pérdida "de su condición de premisa existencial" humana para transformar en algo apenas "recuperado y recuperable en el mercado de los bienes de consumo".

La idea, intencionalmente suscitada en el imaginario popular, de que sería posible obtener salud, a través del acceso a las actividades corporales ofrecidas en esa brecha del mercado, refuerza la noción simbólica de la "salud conquistada", ya sea por el hecho de involucrarse en sus prácticas, ya sea por la utilización de los productos a ellas agregadas.

Pero tal perspectiva, en la sociedad capitalista y globalizada contemporánea pretende ampliar más aún esa dependencia. Según Lefevre (1991), para ofrecer a la salud como una mercadería, es necesario que se amplíe el grado de necesidad. Además de eso, es importante que esa necesidad sea vista como algo natural, abstracto, igual para todas las clases sociales. De esta forma, el consumo se transforma en un acto únicamente individual de satisfacción de necesidades dentro del poder adquisitivo de cada uno.

Si asumimos la coherencia de esta noción, se vuelve comprensible la razón por la cual los elementos circunscritos en el universo del fitness y de la exaltación del cuerpo alcanzaron una dimensión "abrumadora" en contexto sociológico de la actualidad (LUZ, 2005). La publicidad, propaganda y marketing a través de los medios de comunicación de masa completan la corriente que une el proceso de producción de esas mercaderías al de la creación de los deseos y aspiraciones de obtenerlas.

\section{Otras delimitaciones al significado de salud}

Al contrario del enfoque limitado de la salud que las corrientes hegemónicas de la Educación Física tiene adoptado, permitiendo para si un papel difusor de ideas llanas y simplistas del tipo "practique ejercicio físico y gane salud", las dimensiones 
relacionadas entre la salud y la sociedad han sido provechosas debatidas por otras áreas del conocimiento. Del punto de vista de las relaciones de producción, existen perspectivas que le otorgan privilegio, principalmente, a las condiciones de salud de las clases pobres y trabajadoras (ENGELS, 1988; MOURA, 1989; GRANDA; BREILH, 1989; FLEURY, 1992; DEJOURS, 2002).

Varias críticas densas también fueron formuladas en relación al proceso de tecnificación de la medicina, al poder de monopolio de las grandes organizaciones corporativas fabricantes de remedios y la medicalización social (ILLICH, 1982; CASTIEL, 1994; LEFÈVRE, 1999; BOLTANSKI, 2004; BUNTON; BURROWS, 2004).

Así, para que no se vuelva un ejercicio intelectual vacío de propósito "concebir" salud no puede representar únicamente la búsqueda por la comprensión de terminologías y sus sentidos semánticos, pero antes, la consideración de la complejidad de factores entrecruzados - económicos, políticos y culturales - que los atraviesan y la atribución de sentido de las repercusiones sociales que de allí se derivan (BREILH, 1991). Y aún que se adopten determinadas nociones para expresarla, es necesario reconocer que "definiciones", "taxonomías" y sus afines, son solamente instrumentos subjetivos empleados para contribuir en el intento de capturar el (los) significado(s) de determinado fenómeno, lo que no siempre resulta plausible. De ese modo, por más "elaborado" que sea el concepto, se trata apenas de una representación simbólica imperfecta y parcial de la realidad.

Sin embargo, uno de "nosotros" que persiste en el juicio de las prioridades de la investigación en la salud, en algunas áreas académicas que la subordinan a sus preceptos definitorios, tal vez sea el uso indiscriminado de nociones jerárquicas y clasificadoras, como forma de interpretar (o de reducir) los problemas que interfieren en las condiciones de vida humana. Eso se vuelve todavía más complicado en la perspectiva de las formulaciones de políticas de intervención social para el enfrentamiento de los problemas sanitarios, en relación a los aspectos concretos de lo cotidiano son, de cierto modo, subvalorados como criterios guiadores de las preocupaciones, en prejuicio de la exaltación de las "herramientas operativas" abstractas y de carácter peligrosamente homogéneo. A título de ejemplo, es válido citar el reciente empleo, en escala mundial, de criterios válidos para "medir" "calidad de vida" (lo que ya es, como mínimo, una paradoja lingüística ${ }^{8}$ ) aplicados indistintamente, en países ricos y pobres (MINAYO et al., 2000). 
Este panorama pone en evidencia, por lo tanto, opciones valorativas de parte de la comunidad científica, las cuales tienen determinado un direccionamiento preferencial por la "operacionalización" de esos conceptos en la salud (y por el agregado de su "arsenal utilitarista") y no por intermedio del abordaje de otras posibles interfaces metodológicas que se acerquen más a la realidad, hecho bastante significativo. Con toda cautela, es necesario recordar que la ciencia se caracteriza, antes que nada, como una de las actividades más genuinas y representativas de la cultura humana, a pesar que su dimensión iluminista utópica de un prometedor progreso extendido a toda la población mundial - anunciado, sobretodo por la ciencia médica - se haya perdido en su discurso histórico.

En ese sentido, al analizar con más detenimiento la actuación epidemiológica en las investigaciones de la salud, José da Rocha Carvalheiro admite que no siempre ella se dirige, de hecho, a lo "colectivo" de la población tomado como objeto de la investigación. Él afirma que "frecuentemente, este colectivo es meramente estratégico para superar la variabilidad biológica individual” (GRANDA; BREILH, 1989, p. 1). Y continua: "una descripción de este objeto, con base científica, nunca es neutra (subrayado nuestro). Tiene que ver con la concepción de mundo del investigador, con la teoría que está por detrás de su concepción de la sociedad. Tradicionalmente, la población es tratada, por la Epidemiología y por la propia Demografía, como un todo homogéneo." (GRANDA; BREILH, 1989, p. 2).

Almeida-Filho (1992, p. 25) completa tal percepción al elaborar comentarios críticos sobre el eje guía de la epidemiología en la década de 1980:

para los epidemiólogos, la naturaleza esencialmente empirista de su práctica científica se presenta como un supuesto fundamental, axiomático, indiscutible. Empirismo se refiere en este caso al referencial [...] que tomaría la realidad sin intermediarios, siendo los conceptos científicos inmediatamente reducidos a la observación.

Para el autor, la práctica disciplinar del campo de la epidemiología en la actualidad parece no haber abandonado esa percepción, que se destaca en el aforismo de John Locke: "No direct measurement, no basic concept". (p. 26); o sea, solamente aquello que sea mensurable puede ser objeto de un tratamiento científico. Bajo esta concepción, solo sería posible conceder una "aprobación científica" para cualquier fenómeno estudiado, se fuese viable crear indicadores cuantificables. Esa creencia se basa en la concepción positivista de ciencia, que se considera neutra, libre de juicios de valor. Para Minayo (1993), ese fue el hilo conductor que terminó 
por fortalecer el empleo de términos matemáticos en las investigaciones del área, como el lenguaje de las variables y la sistematización de los métodos cuantitativos.

Mantener una postura crítica, cuestionarnos permanentemente sobre los dictámenes certificadores de las corrientes hegemónicas en la investigación constituye una necesidad urgente, no sólo en el campo de la salud. Hasta porque, se multiplican todo el tiempo las estrategias de entidades internacionales (Organización Mundial de la Salud, por ejemplo) que, a partir de resultados en estudios epidemiológicos, han buscado establecer a nivel mundial, que formas de comportamientos pueden ser consideradas "saludables" y de "riesgo" para las personas (a saber, campañas de prevención de la SIDA, contra el cigarrillo, el sedentarismo, etc). Sin embargo, más que recomendaciones para la salud, tales normas engendran con sutilezas, aspectos descontextualizados, prejuiciosos y elitistas, ya que no siempre sus divulgaciones están acorde con todos los diferentes niveles sociales de las naciones que las adoptan.

En tiempos de una peligrosa fusión entre los avances tecnológicos de la biomedicina, los medios de comunicación y el mercado no hay como negar que nuestras vidas están invadidas diariamente en el escenario contemporáneo, con la promulgación de "discursos cientificistas" casi invencibles, especialmente se tomamos en cuenta las cuestiones relativas al proceso salud-enfermedad-cuidado.

Cabe recordar las palabras de Nogueira (2003, p. 27), cuando destaca una de las críticas principales del sagaz intelectual Ivan Illich, que hace relación a la modernidad médica y su exacerbada tecnificación instrumental:

el consumo intensivo de la medicina moderna es una forma de dependencia, en el sentido específico de dependencia a una droga. Esa forma de dependencia está asegurada, de un lado, por el monopolio del ejercicio profesional de los médicos $y$, de otro, por la confianza que los no entendidos en la materia depositan gratuitamente en los agentes de la medicina.

Otro aspecto de esa nueva configuración híbrida de la salud humana en el siglo XX, se refiere al Proyecto Genoma ${ }^{9}$, cuyos descubrimientos ya alcanzaron gran notoriedad por la divulgación en los medios de comunicación en masa. Son conocidas las promesas hechas en público por los científicos, de cómo la ingeniería genética podrá "modificar positivamente" la salud de "toda" la población mundial (SFEZ, 1995). Esas afirmaciones dejan escapar, intencionalmente, un sentido futurista engañoso de predominio en relación al supuesto acceso mayoritario de 
las personas a los favores proporcionados por la manipulación genética, hecho que en parte, no resulta creíble, considerando el alto costo de las técnicas y productos pertenecientes a la mega-industria de la biotecnología y, la desigualdad socioeconómica instaurada en el mundo, sobretodo en los países pobres (KOTTOW, 2002; CARDOSO; CASTIEL, 2003). En síntesis, es razonable decir que la mayor parte de las personas solo podrá resultar beneficiada en el caso de que tuviera poder adquisitivo para pagar por el "consumo" de tales servicios.

Aún delante de algunas supuestas incongruencias dispuestas en el panorama lato sensu de la salud (a veces, de forma velada), no sería sensato maldecir el papel de la ciencia y de los investigadores en el intento de conseguir "avances" para minimizar males o enfermedades de la colectividad humana. No se trata de eso. Pero, es necesario reconocer que, antes que nada, el empleo destinado a los descubrimientos científicos, así como también la decisión de que debe ser investigado (donde, porque, para que y para quién), son sin opciones valorativas legítimas de la voluntad humana y, por lo tanto, parciales e intrínsecamente sujetas a errores y preferencias de juicio personal.

Es tarea igualmente imprescindible a la comunidad académica, suscitar mecanismo para que las diferentes áreas del conocimiento establezcan un criterioso y duradero ejercicio de la reflexión, en la identificación de los juicios que subyacen a las concepciones de la salud defendidas por sus profesionales, puesto que son esos aspectos que orientam las prioridades en los respectivos campos de intervención social.

¿Es posible que a pesar de lo que ya fue expuesto hasta aquí, todavía cabría preguntarse, pero al final de cuentas, qué es la salud? Aún corriendo el riesgo de una probable imprecisión, creemos en la connotación adoptada por las disciplinas de Salud Colectiva y de Ciencias Sociales en Salud que promulgan ser una conjunto de elementos asociados a suplir las necesidades humanas. Complementariamente, el marco histórico brasileño - político y social - de la VIII Conferencia Nacional de la Salud realizada en 1986, le otorga un significado relevante al fenómeno (superando inclusive, otras concepciones dicotómicas ${ }^{10}$ difundidas anteriormente por la OMS): en sentido más amplio, la salud es la

resultante de las condiciones de alimentación, vivienda, educación, poder adquisitivo, medio ambiente, trabajo, transporte, empleo, recreación, libertad, acceso y posesión de la tierra y acceso a los servicios de la salud. Por ello, antes que nada, es resultado 
de las formas de organización social de la producción, las cuales pueden generar desigualdades en los niveles de vida (FLEURY, 1992, p. 170).

\section{Ivan Illich piensa que}

la salud designa un proceso de adaptación. No es el resultado de instinto, sino una reacción autónoma, pero moldeada culturalmente, delante de la realidad socialmente creada. Ella designa la habilidad de adaptarse a los ambientes cambiantes, al crecimiento y al envejecimiento, a la cura cuando se está enfermo, al sufrimiento y a la expectativa pacífica de la muerte. La salud abarca el futuro también y, por lo tanto, incluye la angustia así también como los recursos internos como para convivir con ella (NOGUEIRA, 2003, p. 5).

\section{Subrayamos una última interpretación de Dejours (1986, p. 11):}

La salud es la libertad de dar al cuerpo [...] de comer cuando tiene hambre, de hacerlo dormir cuando tiene sueño, de darle azúcar cuando baja la glucemia. No es normal estar cansado o tener sueño, no es normal tener una gripe [...] Puede hasta ser normal tener algunas dolencias. Lo que no es normal es no poder cuidar de esa dolencia, no poder ir a la cama, dejarse llevar por la dolencia.

La complejidad que atraviesa el breve panorama de recortes bosquejado en el texto, nos conduce a pensar que no es una tarea fácil analizar o intentar "concebir" la salud. Pero, juzgamos que se hace necesario apostar a las perspectivas de interpretación del fenómeno a partir de una visión menos centrada en el paradigma biomédico y más atento a los cuerpos sociales. Esto si, de hecho, queremos atribuirle su primordial significado como representante legítimo de aspiraciones, ideas y prácticas convergentes a la mejoría de las condiciones de la vida humana en un sentido más amplio; si realmente, pretendemos valernos de estrategias para la superación de los problemas y los males colectivos de la "salud social", en prejuicio del "contexto individualista-privado" que prevé y privilegia la resolución de los problemas de la salud, a priori, para quien puede pagar por ella.

Guiarnos en esta desafiante tarea de reinterpretación de los sentidos de la salud a partir de algunos supuestos y experiencias producidas e acumulados por la Salud Colectiva, puede ser bastante prometedor, especialmente siendo la Educación Física un área cuya matriz teórico-científica todavía es breve y está en formación, pero, más aún porque, en rigor, poco ha invertido en las problemáticas que atraviesan la dimensión sociológica de la salud. 
En este sentido, es importante que la Educación Física brasileña reconozca el campo de la "Salud Colectiva" como un agregado de conceptos y practicas que designan a la salud como fenómeno social y por lo tanto, de interés público. Y que los orígenes del Movimiento de constitución de esa área se remontan al trabajo teórico y político emprendido por investigadores de departamentos de instituciones universitarias y de escuelas de la Salud Pública de América Latina e de Brasil, en particular, a lo largo de las dos últimas décadas. La provechosa actividad desarrollada en el campo científico de la Salud Colectiva dio soporte a un debate político iniciado a mediados de 1970 en torno de la crisis de la salud, contextualizada en las luchas ideológicas del país en aquellos tiempos. Ese movimiento se difundió entre los más diferentes foros organizacionales de la sociedad, contribuyendo para la formulación y la ejecución de un conjunto de cambios identificados como la Reforma Sanitaria Brasileña (PAIM; ALMEIDA-FILHO, 2000).

Las propuestas de ese Movimiento incluyeron un cambio significativo en el concepto de salud, al postular cambios en el modelo de gerencial, organizativo y operativo del sistema de servicios públicos de la salud, en la formación y capacitación del personal en el sector, en el desarrollo científico y tecnológico en esta área y, principalmente, en los niveles de participación crítica y creativa de los diversos actores involucrados en el proceso de reorientación de las políticas económicas, sociales y sanitarias, teniendo en vista la mejoría de los niveles de vida y la reducción de las profundas desigualdades sociales ya instaladas en el país.

\section{Consideraciones finales}

Hechas esas consideraciones, tal vez sea prudente hacer una salvedad sobre un último tema. Cuando sugerimos un acercamiento interdisciplinario (teóricometodológico) entre la Salud Colectiva y la Educación Física, no significa que deseemos no considerar o excluir los conocimientos fisiológicos inherentes a los aspectos de la salud y la enfermedad, que son sabidos relevantes. La pretensión, de hecho, es exaltar la prometedora aproximación entre las dimensiones socioculturales y económicas y las de carácter más individual o biológico en las incursiones que investiguen la salud, con la perspectiva de incitar a los investigadores de la Educación Física a darse cuenta de la posibilidad de producirse interpretaciones más consistentes de la realidad, en esos estudios temáticos. 
Ya hay buenos indicios entre nuestros pares de que tal vez la Educación Física en Brasil estea dando muestras de su madurez como campo científico y de la intervención, inclusive, derivada de un cuestionamiento más vehemente sobre su pertenencia exclusiva a un papel mayoritario de promotor de actividades físicas. Entendemos que para poder reconocerse, efectivamente, como el área perteneciente al campo de la Salud Colectiva, la Educación Física brasileña necesita incorporar un cambio crítico del propio concepto de salud que ha "defendido" resaltando antes que nada, las interrelaciones con la equidad social, postura que, de ninguna manera, la hará perder su especificidad y legitimidad frente a las cuestiones de motricidad humana. Parece coherente admitir que para ocurrir tal avance, el área necesite luchar contra todo el arsenal de discursos y acciones pragmáticas moralizadoras utilizados para "combatir el sedentarismo", idea que se volvió la imagen del área en la última década.

Vivimos en una cierta intensificación mensurable en los días de hoy, principalmente, en relación a las prácticas de prevención de las enfermedades, propagadas por la biomedicina (y sus dimensiones correlativas). Sin embargo, a pesar de que los nuevos instrumentos permitan explicar, cada vez mejor, distintos fenómenos fisiológicos del proceso salud-enfermedad en el organismo humano, simultáneamente, esa "euforia" de avances sucesivos tecnocientíficos ha dejado mucho atrás, perdiendo de vista, la preocupación por la condición de la vida humana, más que nada en su dimensión colectiva. Cabe preguntarse si la Educación Física, como área o disciplina que hace llamar científica, subyugada y subyacente a esa euforia de conquistas e innovaciones tecnoinstrumentales "inagotables", no ha reforzado tal visión (en vez de cuestionarla)?

Ya es tiempo de asumir una postura crítica, tratando de desarrollar, con toda cautela y perplejidad necesario, un diálogo con otras disciplinas, principalmente aquellas que privilegien las cuestiones relacionadas por las desigualdades sociales en la actualidad, para no aceptarlas como un curso natural de la historia de la humanidad.

La Educación Física posicionada como campo de actuación social y científica pero limitada en su práctica, donde todavía predominan visiones mensurables que pretenden "clasificar" comportamientos de riesgo y de salud (FRAGA, 2003b; 2006), necesita de una actitud crítica por parte de los profesionales para reflexionar sobre las cuestiones expuestas. 


\section{Referencias}

ALMEIDA-FILHO, N. A Clinica e a epidemiologia. Salvador: Apce/Abrasco, 1992.

AZEVEDO, F. Da educação physica. São Paulo: Melhoramentos, 1920.

BREILH, J. Epidemiologia: economia, política e saúde. São Paulo: Unesp/Hucitec. 1991.

BOLTANSKI, L. As classes sociais e o corpo. 4. ed. São Paulo: Paz e Terra, 2004.

BUNTON, R.; BURROWS, R. Consumption and health in the "epidemiological" clinic of late modern medicine. In: BUNTON, R.; NETTLETON, S.; BURROWS, R. (Org.). The sociology of health promotion: critical analyses of consumption, lifestyle and risk. London: Routledge, 2004. p. 206-222.

CARDOSO, M. H. C. A.; CASTIEL, L. D. Saúde coletiva, nova genética e eugenia do mercado. Cadernos de Saúde Pública, v. 19, n. 2, p. 653-662, 2003.

CASTIEL, L. D. O buraco e o avestruz: a singularidade do adoecer humano. Campinas: Papirus, 1994. A medida do possível: risco e saúde. In: CICLO DE CONFERÊNCIAS “A SAÚDE EM DEBATE NA EDUCAÇÃO FÍSICA”. 1. Coleção de Videos... Campinas: GTT1/ CBCE. 2002. FITA 2 (120 min), VHS, son., color.

. Quem vive mais, morre menos?: estilos de risco e promoção de saúde. In: BAGRICHEVSKY, M.; PALMA, A.; ESTEVÃO, A. (Org.). A saúde em debate na educação física. Blumenau: Edibes, 2003. p. 79-97.

CASTIEL, L. D.; VASCONCELLOS-SILVA, P. R. A noção “estilo de vida” em promoção de saúde: um exercício crítico de "sensibilidade epistemológica". In: BAGRICHEVSKY, M.; PALMA, A.; ESTEVÃO, A.; DA ROS, M. (Org.). A saúde em debate na educação física, v. 2. Blumenau: Edibes, 2006. p. 68-90.

COSTA, E. M. B.; VENÂNCIO, S. Atividade física e saúde: discursos que controlam o corpo. Revista Pensar a Prática, v. 7, n. 1, p. 59-74, 2004.

COURTINE, J-J. Os Stakhanovistas do narcisismo: body-building e puritanismo ostentatório na cultura americana do corpo. In: SANT’ANNA, D. B. (Org.). Políticas do corpo. São Paulo: Estação Liberdade, 1995. p. 81-114.

DEJOURS, C. A loucura do trabalho. 5. ed. São Paulo: Cortez, 2002.

. Por um novo conceito de saúde. Revista Brasileira de Saúde Ocupacional, v. 54, n. 14, p. 7-11, 1986.

ENGELS, F. A situação da classe trabalhadora na Inglaterra. 2. ed. São Paulo: Global. 1988.

FERREIRA, A. B. H. Novo dicionário da lingua portuguesa. 2. ed. Rio de Janeiro: Nova Fronteira, 1986. p. 1424. 
FLEURY, S. (Org.). Saúde: coletiva? Questionando a onipotência do social. Rio de Janeiro: RelumeDumará. 1992.

FOUCAULT, M. História da sexualidade I: a vontade de saber. 13. ed. Rio de Janeiro: Graal, 1999.

FRAGA, A. B. A boa forma de João e o estilo de vida de Fernanda. In: LOURO, G. L.; NECKEL, J. F.; GOELLNER, S. V. (Org.). Corpo, gênero e sexualidade. Petrópolis: Vozes, 2003b. p. 95-107.

FRAGA, A. B. Espectros de Antinoüs: educação do físico e governo dos corpos no Brasil. Revista Iberoamericana, n. 10, p. 103-112, 2003a.

O exercício da informação: governo dos corpos no mercado da vida ativa. Campinas: Autores Associados, 2006.

GÓIS JÚNIOR, E.; LOVISOLO, H. Descontinuidades e continuidades do movimento higienista no Brasil do século XX. Revista Brasileira de Ciências do Esporte, v. 25, n. 1, p. 41-54, 2003.

GOLDENBERG, M.; RAMOS, M. S. A civilização das formas: O corpo como valor. In: GOLDENBERG, M. (Org.). Nu e vestido. Rio de Janeiro: Record, 2002. p. 19-40.

GRANDA, E.; BREILH, J. Saúde na sociedade. 2. ed. São Paulo: Cortez. 1989.

ILLICH, I. A expropriação da saúde: nêmesis da medicina. 5. ed. Rio de Janeiro: Forense, 1982.

KOTTOW, M. Salud pública, genética y ética. Revista de Saúde Pública, v. 36, n. 5, p. 537-544, 2002.

LEFÈVRE, F. O medicamento como mercadoria simbólica. São Paulo: Cortez, 1991. . Mitologia sanitária: saúde, doença, mídia e linguagem. São Paulo: Edusp, 1999.

LOVISOLO, H. Personal training: estética, utilidade e moralidade. Revista Artus, v. 19, n. 1, p. 1422, 1999.

LUZ, M. Novos saberes epráticas em saúde coletiva: estudo sobre racionalidades médicas e atividades corporais. 2. ed. São Paulo: Hucitec, 2005.

MINAYO, M. C. O desafio do conhecimento: pesquisa qualitativa em saúde. 2. ed. São Paulo: Hucitec/Abrasco, 1993.

MINAYO, M. C. S.; HARTZ, Z. M. A.; BUSS, P. M. Qualidade de vida e saúde: um debate necessário. Ciência \& Saúde Coletiva, v. 5, n. 1, p. 7-18, 2000.

MIRA, C. M. O declínio de um paradigma: ensaio crítico sobre a relação de causalidade entre exercício físico e saúde. 2000. Tese (Doutorado em Educação Física)-Faculdade de Educação Física, Universidade Gama Filho, Rio de Janeiro, 2000.

MOURA, D. Saúde não se dá, conquista-se. São Paulo: Hucitec, 1989.

NOGUEIRA, L.; PALMA, A. Reflexões acerca das políticas de promoção de atividade física e saúde: uma questão histórica. Revista Brasileira de Ciências do Esporte, v. 24, n. 3, p. 103-119, 2003. 
NOGUEIRA, R. P. A saúde pelo avesso. Natal: Seminare, 2003.

PAIM, J. S.; ALMEIDA-FILHO, N. A crise da saúde pública e a utopia da saúde coletiva. Salvador: Casa da Qualidade, 2000.

PALMA, A. Atividade física, processo saúde-doença e condiçōes sócio-econômicas: uma revisão da literatura. Revista Paulista de Educação Física, v. 14, n. 1, p. 97-106, 2000.

PALMA, A.; FERREIRA, D. C.; BAGRICHEVSKY, M.; RESENDE, H. G. Dimensões epidemiológicas associativas entre indicadores sócio-econômicos de vida e prática de exercícios físicos. Revista Brasileira de Ciências do Esporte, v. 27, n. 3, p. 119-136, 2006.

PALMA, A.; SALOMÃO, L. C.; NICOLODI, A. G.; CALDAS, A. Reflexōes acerca da adesão aos exercícios físicos: comportamento de risco ou vulnerabilidade?. Revista Movimento, v. 10, n. 21, p. 83-100, 2003.

PEDRAZ, M. V. El cuerpo preso da la vida saludable: la construcción de una ética médicodesportiva de sujeción. Revista Brasileira de Ciências do Esporte, v. 27, n. 3, p. 23-37, 2006.

RESTREPO, H. E. Conceptos y definiciones. In: RESTREPO, H. E.; MÁLAGA, H. (Org.). Promoción de la salud: cómo construir vida saludable. Bogotá: Médica Panamericana, 2001. p. 24-33.

SEGRE, M.; FERRAZ, F. C. O conceito de saúde. Revista de Saúde Pública, v. 31, n. 5, p. 538542, 1997.

SFEZ, L. A saúde perfeita: crítica a uma nova utopia. São Paulo: Unimarco/ Loyola, 1995.

SOARES, C. Educação fisica: raízes européias e Brasil. 3. ed. Campinas: Autores Associados, 2003.

\section{Notas}

${ }^{1}<$ www.abrasco.org.br>.

${ }^{2}<$ www.redeunida.org.br>.

${ }^{3}$ Espacio institucional importante que ha promulgado debates y avances fundamentales en el proyecto de la Reforma Sanitaria Brasilera y que, inclusive, viene registrando la ascensión efectiva de varios profesionales provenientes de las ciencias humanas y sociales en la conducción de proposiciones significativas en el proceso histórico de reformulación de políticas de la salud en el país.

${ }^{4}$ Centro Brasilero de Estudios de la Salud (http://cedoc.ensp.fiocruz.br/cebes/).

${ }^{5}$ Siguiendo los preceptos difundidos en los medios de masa, esa sería objeto y producto modelo deseable para la industria de la belleza, moda y fitness.

${ }^{6}$ También propagado como sinónimo de económicamente productivo, ya que para tales discursos, en tesis, disminuiría el ausentismo en los puestos de trabajo e los costos del Estado en el destino de los fondos para la salud pública. Además de ser poco probable constatar esas premisas por medio de 
investigaciones con criterios consistentes, es necesario afirmar que la vida y la salud de las personas no pueden estar reducidas a una perspectiva de planificación financiera, de relación costo-beneficio.

${ }^{7}$ A respecto de la subjetividad de ese concepto y de las incongruencias inherentes a su empleo en el contexto de la salud, verificar los comentarios de Segre y Ferraz (1997)

${ }^{8}$ Según Ferreira (1986), cualidad es un sustantivo femenino; aspecto sensible, y que no puede ser medido (subrayado nuestro), de las cosas". (p. 1424)

${ }^{9}$ Lucien Sfez (1995) en su obra titulada "La salud perfecta: crítica a una nueva utopía", defiende la idea de que en frente al fracaso de las promesas iluministas de la ciencia surge una nueva dimensión utópica de la humana en el cambio de siglo, constituida por los Proyectos Biosfera II, Artificial Life e Genoma, que representarían una búsqueda desenfrenada por la eterna juventud y por la cura de las enfermedades que acechan al hombre y al ecosistema del planeta.

${ }^{10}$ La Organización Mundial de la Salud (OMS) dice que la salud "es un estado de completo bienestar físico, mental y social y no apenas la ausencia de enfermedad o dolencia”; tal concepción se muestra "estática" e imposible de ser alcanzada, puesto que interpreta el "fenómeno" salud a partir de un proceso dinámico, donde la enfermedad sería una nueva dimensión de la vida y, por lo tanto, no podrían estar separadas una de la otra. De todos modos, todavía hay una necesidad de considerar que "bienestar completo" expresa la ausencia total de problemas, idea utópica para la condición humana (NOGUEIRA, PALMA, 2003). 
Physical Education and its Insertion in the Collective Health Field: Searching for a Critical Dialogue about Interfaces, Aptness and Senses

This essay aims to rise a critical reflection about the health and body conceptions in the Brazilian Physical Education (PE), also examining its limitations and necessities in the thematic researches linked to this conceptions, with the objective to suggest contextual elements to approach the area with the Collective Health field. More recently PE has been inserting in public health services as systematic physical activities (PA) promoter. In the some way, PE and PA have been considering the same. This paper aims to question this misunderstanding, although it recognizes discipline historic traces of PE in its militarist genesis which partially justify this reductionism comprehension. It also proposes a brief analysis about the "body-health-market" theme. Finally, it shows that the constitutive premises of Collective Health can offer valuable epistemological and political perspectives to legitimate researchers and professionals of $\mathrm{PE}$ as promoters of ethical knowledge and body practices in health, respecting and considering socioeconomic and cultural diversity in their interventions in the population.

> Key words: health conceptions; body culture; physical education; Collective Health. 